\title{
High Frequency Transduction of Resistance to Ampicillin and Kanamycin in Proteus mirabilis
}

\author{
By J. N. COETZEE \\ Department of Microbiology, University of Pretoria, \\ Republic of South Africa
}

(Received 4 October 1974)

INTRODUCTION

Transduction of the T compatibility group plasmid R394 (Coetzee, Datta \& Hedges, I972; Coetzee, Datta, Hedges \& Appelbaum, I973) by Proteus mirabilis phage 34 (Coetzee \& Sacks, 1960) to P. mirabilis strain PM5006 yielded some transductants which were only kanamycin resistant (Coetzee, I974 b). These failed to transmit their resistance by conjugation but transferred resistance by transduction to strains that adsorbed phage 34 or phage $5006 \mathrm{M}$, a serologically identical phage derived from PM5006 in which it exists as a cryptic prophage (Krizsanovich, I973). Transductants liberated a phage, either spontaneously or after u.v. induction, serologically identical to these two phages. The induced phage transduced kanamycin resistance to PM5006 at a frequency of $3 \times 10^{-2} /$ plaque-forming unit (p.f.u.) adsorbed (Coetzee, I $974 b$ ). The frequency could be increased about tenfold with the use of $5006 \mathrm{M}$ as helper phage. This paper shows that the ampicillin-resistance region of R394 can recombine with the genome of this high frequency transducing (h.f.t.) phage to allow high frequency transduction of both ampicillin and kanamycin resistance.

\section{METHODS}

Bacteria, plasmids and phage. These are listed in Table I.

Media, antibiotics, conjugal transfer of plasmids, coexistence of plasmids, selection of bacteria in which segregation of markers had occurred, phage neutralization, ultraviolet irradiation of phage lysates, phage induction and transduction techniques. These were exactly as described previously (Coetzee, 1974b).

\section{RESULTS}

The R394 plasmid was transferred to PM5006 $(\overline{\mathrm{R} 394})$ from J53-I (R394) by conjugation. Exconjugants were selected on ampicillin-kanamycin agar to which tetracycline was added to counterselect against the donor. The ampicillin-resistance donor marker was transferred at a frequency of $10^{-4} /$ donor bacterium. Twenty exconjugants, designated PM5006( $\overline{\mathrm{R}} 394$ R394), were purified by streaking on the same agar. All transferred both ampicillin and kanamycin resistance at a frequency of $5 \times 10^{-4} /$ donor bacterium to recipient $\mathrm{J} 53^{-\mathrm{I}}$, confirming that they carried the R394 plasmid. On induction with u.v. light all 20 yielded lysates containing about $10^{9}$ p.f.u./ $/ \mathrm{ml}$ on PM5006. In transduction experiments, with selection on kanamycin agar or on ampicillin-kanamycin agar which had been spread with a potent phage 34 antiserum, I 8 of the 20 lysates transduced only kanamycin resistance with a high frequency to PM5006. This confirmed the previous finding (Coetzee, I974b) that the prophage bearing 
Table I. Bacteria, plasmids and phage

Bacteria

Proteus mirabilis PM5006

P. mirabilis PM5006trp-I

$P$. mirabilis PM5006arg-I nal-r

P. mirabilis PM5006tyr-I str-r

P. mirabilis PM5006pyrBI nal-r

Escherichia coli J53-I

Plasmids and hosts

J53-I (R394)

PM5006( $(\overline{\mathrm{R} 394})$

Bacteriophage

5006M. PM5006
Properties*

Recipient for general transducing phage 34. Cryptically lysogenic for an identical phage, 5006M. T resistant

Auxotrophic mutants of PM5006

nal-r mutant of $\mathrm{j}_{53}$, an $\mathrm{F}^{-} l a c^{+}$, pro, met mutant of $E$. coli $\mathrm{K} 12$

R394 introduced by conjugation. R394 is a T compatibility group plasmid with resistance markers $\mathrm{A}, \mathrm{K}$

Superior line indicates that the plasmid was introduced by transduction. The vector was phage 34 . K resistant; u.v. induction yields h.f.t. phage for $\mathrm{K}$ resistance

Phage 5006M produced on PM5006 by lytic infection. On lysogenization converts host to non-adsorption of homologous phage
Reference

Coetzee \& Sacks ( I 960), Coetzee \& Smit (1970), Coetzee (1974a, $b, c)$ Krizsanovich (I973)

Coetzee (I974c)

Coetzee et al. (1972)

Coetzee et al. (1972)

Coetzee $(1974 b)$

Krizsanovich (1973), Coetzee (I974b)

* Symbols designate resistance to: A, ampicillin; K, kanamycin; nal-r, nalidixic acid; str-r, streptomycin; $T$, tetracycline.

Table 2. Transduction of markers by an u.v. induced lysate of PM5006 $(\overline{\mathrm{R} 394})$ and the effect of helper phage, phage 5006M.PM5006

Suitable dilutions of phage suspensions in saline $(0.1 \mathrm{ml})$ were added to $2 \mathrm{ml}$ logarithmically growing cultures of recipients at $30{ }^{\circ} \mathrm{C}$ for $10 \mathrm{~min}$. Adsorption mixtures were appropriately diluted in saline and samples passed through membrane filters. Prototrophic transductants were selected immediately by placing membranes in minimal media. For selection for antibiotic resistance, membranes were incubated on nutrient agar for $\mathrm{I} h$ before transfer to MacConkey agar containing $50 \mu \mathrm{g}$ each of $A$ plus $\mathrm{K} / \mathrm{ml}$.

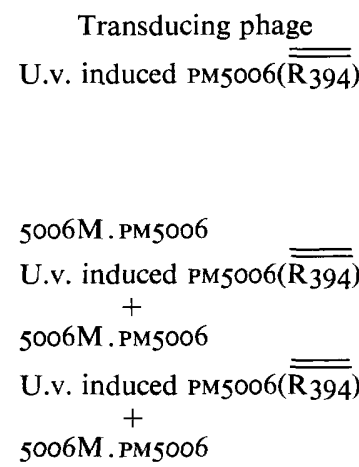

$$
\left.\begin{array}{l}
\text { M.o.i. } \\
0.05 \\
0.06 \\
0.08 \\
0.05 \\
0.09 \\
3.1 \\
0.05 \\
3.0
\end{array}\right\}
$$

$\left.\begin{array}{c}0.07 \\ 3.2\end{array}\right\}$
Transduction frequency/ p.f.u. adsorbed

$\quad$ Recipient
PM5006
PM5006trp-I
PM5006arg-I nal-r
PM5006tyr-I str-r
PM5006 pyrBI nal-r
PM5006trp-I
PM5006

$A$ and $\mathrm{K}$ Prototrophy

$4 \times 10^{-2}$

$4 \times 10^{-2}$

$4 \times 10^{-2}$

$3 \times 10^{-2}$

$3 \times 10^{-2}$

$<1 \times 10^{-10}$

$1 \times 10^{-8}$

$3 \times 10^{-8}$

$4 \times 10^{-8}$

$4 \times 10^{-8}$

$5 \times 10^{-8}$

$5 \times 10^{-1}$

$5 \times 10^{-1}$

$5 \times 10^{-8}$ 
the kanamycin-resistance region of R394 may coexist with plasmids of the same compatibility group. Two of the 20 lysates, used at a multiplicity of infection (m.o.i.) of $<0.1$, co-transduced ampicillin and kanamycin resistance to PM5006 at a frequency of $4 \times 10^{-2} / p$.f.u. adsorbed. No minute colonies suggestive of abortive transductants were observed.

Ten of the ampicillin- and kanamycin-resistant transductants, picked off plates on which a $\mathrm{IO}^{-5}$ dilution of the adsorption mixture had been inoculated, were purified by restreaking on the same agar. These transductants, designated PM5006 $\left(\overline{\overline{\mathrm{R}_{394}}}\right)$, had identical properties. They did not transmit either marker conjugally to J53-I. Despite the fact that they originated from singly-infected cells and that precautions were taken to prevent secondary infection, they liberated phage $5006 \mathrm{M}$ spontaneously, and on u.v. induction produced h.f.t. lysates capable of co-transducing both resistance markers to PM5006. Like PM5006 $(\overline{\mathrm{R} 394})$ these transductants did not absorb phage $5006 \mathrm{M}$, presumably as a result of lysogenic conversion (Coetzee, 1961; Coetzee, 1974b).

Phage $5006 \mathrm{M}$ employed as helper, increased the transduction frequency from $4 \times 10^{-2}$ to $5 \times 10^{-1} /$ p.f.u. adsorbed (Table 2). Lysates were also capable of generalized transduction. The slope of the curve relating transduction frequency to m.o.i. of the phage (not shown) indicated that h.f.t. particles were unable to complement one another as was found for a tetracycline-resistance h.f.t. variant of phage P22 (Chan, Botstein, Watanabe \& Ogata, 1972). In these respects the phage resembled the h.f.t. kanamycin-resistance phage (Coetzee, $1974 b)$.

PM5006 $\left(\overline{\overline{R_{394}}}\right)$ segregated ampicillin- and kanamycin-sensitive clones at a frequency of about $5 \times \mathrm{IO}^{-3} /$ bacterium/generation. Segregants were selected for loss of one or other resistance, but invariably both markers were lost simultaneously. They liberated phage spontaneously which was serologically identical to phage $5006 \mathrm{M}$ and did not transduce ampicillin or kanamycin resistance. Segregants resembled transductants in that they too, presumably for the same reason, did not adsorb phage $5006 \mathrm{M}$.

Ultraviolet irradiation of h.f.t. lysates resulted in an exponential decline of transduction frequency at about half the rate at which p.f.u. were inactivated. From this, as well as the high segregation frequency of markers, it was concluded that the h.f.t. phage transduced by lysogenization (Luria, Adams \& Ting, 1960).

\section{DISCUSSION}

Introduction of the $\mathrm{R}_{394}$ plasmid into PM5006 $\left(\overline{\mathrm{R}_{394}}\right)$ led, in 2/20 exconjugants, to recombination between, at least, the ampicillin-resistance region on the plasmid and the h.f.t. phage carrying the kanamycin-resistance marker. Such recombination would, presumably, be facilitated by a region of homology between the two genetic elements which probably exists (Coetzee, $1974 b$ ), and may have occurred at the prophage level or during vegetative growth of the phage (see Schmieger, 1970; Gratia, I973; Wall \& Harriman, 1974). Recombination could involve substitution or addition to the genome of the h.f.t. phage carried by PM5006 $(\overline{\mathrm{R} 394})$, to produce the first h.f.t. to have been described which is capable of conveying resistance to two antibiotics. Apart from the additional marker, the h.f $t$ phage released by PM5006 $\left(\overline{\overline{\mathrm{R}_{394}}}\right)$ resembles the h.f.t. phage released by PM5006 $\left(\overline{\mathrm{R}_{394}}\right)$ in all its properties, and the arguments advanced to explain the behaviour of the latter phage probably apply equally well to the former phage (Coetzee, 1974b).

The author is in receipt of grants from the South African Medical Research Council. 


\section{REFERENCES}

Chan, R. K., Botstein, D., Watanabe, T. \& Ogata, T. (1972). Specialized transduction of tetracycline resistance by phage $\mathrm{P}_{22}$ in Salmonella typhimurium. Virology 50, 883-898.

Coetzee, J. N. (I96I). Lysogenic conversion in the genus Proteus. Nature, London 189, 946-947.

Coetzee, J. N. (1947a). Properties of Proteus and Providence strains harbouring recombinant plasmids between P-lac and Ridrd 19 or R447b. Journal of General Microbiology 80, $119-130$.

Coetzee, J. N. (1974b). High frequency transduction of kanamycin resistance in Proteus mirabilis. Journal of General Microbiology 84, 285-296.

Coetzee, J. N. (1974c). Chromosome transfer in Proteus mirabilis mediated by a hybrid plasmid. Journal of General Microbiology, 86, I33-I46.

Coetzee, J. N., Datta, N. \& Hedges, R. W. (1972). R factors from Proteus rettgeri. Journal of General Microbiology 72, 543-552.

Coetzee, J. N., Datta, N., Hedges, R. W. \& Applebaum, P. C. (1973). Transduction of R factors in Proteus mirabilis and P. rettgeri. Journal of General Microbiology 76, 355-368.

COETZEe, J. N. \& SACKs, T. G. (1960). Transduction of streptomycin resistance in Proteus mirabilis. Journal of General Microbiology 23, 445-455.

Coetzee, J. N. \& Smit, J. A. (1970). Properties of Proteus mirabilis phage I 3vir. Journal of General Virology 9, 247-249.

Gratia, J. P. (I973). Coliphage $ø y$, a novel type of specialized transducer. Molecular and General Genetics I24, I $57-166$.

Krizsanovich, K. (1973). Cryptic lysogeny in Proteus mirabilis. Journal of General Virology 19, 31 I-320.

Luria, S. E., Adams, J. N. \& Ting, R. C. (I960). Transduction of lactose-utilizing ability among strains of $E$. coli and $S$. dysenteriae and the properties of the transducing phage particles. Virology 12, 348-390.

SCHMiEger, H. (1970). The molecular structure of the transducing particles of Salmonella phage P22. II. Density gradient analysis of DNA. Molecular and General Genetics 1o9, 323-337.

Wall, J. D. \& Harriman, P. D. (1974). Phage PI mutants with altered transducing abilities for Escherichia coli. Virology 59, 532-544. 